\title{
Exposure to High-Rise Buildings Negatively Influences Affect: Evidence from Real World and 360-degree Video
}

Robin Mazumder ${ }^{1}$, Hugo J. Spiers ${ }^{2}, *$ Colin G. Ellard ${ }^{1 *}$

1. Department of Psychology, University of Waterloo, Waterloo, Canada

2. Institute of Behavioural Neuroscience, Department of Experimental Psychology, Division of Psychology and Language Sciences, University College London, UK

* contributed equally

Keywords: environmental psychology, psychophysiology, urban design, openness, virtual reality

\begin{abstract}
:
Cities are densifying at a rapid rate, and accordingly, are constructing high-rise buildings to accommodate more people. The aim of this study was to quantify the physiological and psychological impacts of being in the presence of high-rise buildings in Central London, in a real and virtual 360-degree video environment. Using a within-subjects design, participants were exposed to a low-rise and high-rise building. While exposed, participants were monitored for electrodermal activity. They were also administered the Self-Assessment Manikin measure and a cognitive appraisal questionnaire. Participants rated the high-rise building environment to be less open, less friendly and rated themselves to feel less happy and have less sense of control, as compared to low-rise buildings. We found these effects in both the real world $(n=16)$ and a 360degree video setting $(n=121)$. These findings suggest that city environments populated with high-rise buildings can have negative impacts on urban dwellers. Furthermore, this study provides a methodology to examine how individuals respond to the built environment and stands to inform urban design and architectural practices.
\end{abstract}




\section{Introduction}

We are living on a rapidly urbanizing planet; $50 \%$ of the world's population lives in a city, and that number is expected to be $68 \%$ by the year 2050 (United Nations Development Programme, 2014). As more people flock to urban centres, cities are faced with the challenge of accommodating this influx of people. One strategy used to combat outward sprawl is to build upwards. Ali and Kodmany (2012) celebrate high-rise buildings as a key agent in urban densification, citing the benefits of economic development and land preservation. In 2018, 143 skyscrapers were built, at an average height of 247 meters (CTBUH, 2018.) While high-rise buildings can help concentrate population in a small area, they drastically change the cityscape. Conscious of the implications of a shifting skyline, some have taken issue with this transformation. In an effort to preserve architectural heritage, the City of London has historically been restrictive of allowing high-rise buildings (Charney, 2007). In 2007, in a response to such concerns, the Greater London Authority established the London View Management Framework, a formalized mandate to ensure vistas and views of historical sites were not obstructed by highrise buildings (Appert \& Montes, 2015). Despite this framework, the city has continued to build high-rise buildings rapidly, and most have not been built to accommodate housing, but rather business. Between 2000 and 2016, thirty-two skyscrapers were built in Central London and it has been suggested that this was driven by foreign corporate interests that were capitalizing on the plummeting Pound Sterling and establishing their presence in the city (Craggs, 2018). Accordingly, Parker (2013) suggests that skyscrapers are "capital made durable." Regardless of the driving forces, the fact remains that the topography of London's urban landscape is quickly shifting with the upswell of high-rise buildings being built. How does their presence impact the experience of the city? 
Lindal and Hartig (2013) found that building height was negatively correlated with psychological restoration likelihood; this suggests that someone in a state of stress is less likely to feel restored when in the presence of high-rise buildings. It has also been suggested that highrise buildings create a threatening atmosphere that can trigger behavioural freezing and defensive responses (Joye \& Dewitte, 2016). High-rise buildings have also been shown to elicit feelings of oppressiveness (Asgarzadeh et al., 2012). These feelings of oppressiveness have been theorized to cause an invasion of space and invoke feelings of stress and anxiety; however, the psychological and physiological responses have not yet been measured empirically.

Our two-part study aimed to explore how being in the presence of high-rise buildings can influence cognitive appraisal, stress and affect and also to explore new methods for assessing their impact. In the first study, we examined how participants responded emotionally and cognitively to high-rise buildings in Central London. Participants were brought to a high-rise and a low-rise building in Central London; their responses to the two buildings were measured using electrodermal activity (EDA), the Self-Assessment Manikin (SAM) (Bradley \& Lang, 1994), and a cognitive appraisal questionnaire. In the second study, 360-degree video (with audio) was taken of the exact locations used in the first study. Participants were then exposed to the video using immersive virtual reality in the lab; the same measures from the first study were used. The intention of the second study was to further explore how high-rise buildings can influence feelings of oppressiveness, stress and affect, but also to examine whether immersive virtual reality and 360-degree video could be used effectively to elicit similar effects to those found in the real world.

In both studies, we hypothesized that standing in front of a high-rise building, as compared to standing in front of a low-rise building, would yield higher arousal ratings, higher 
valence ratings, higher dominance ratings, higher oppressiveness ratings, lower openness ratings, higher disturbingness ratings, lower openness satisfaction ratings, lower friendliness ratings, higher negative affect ratings, lower positive affect ratings, and higher stress, as measured by electrodermal activity.

\section{Methods}

\section{Study 1}

Participants

A total of 16 participants ( 8 female, average age $=28.95$ years) were recruited from the University College London SONA research pool in August 2018. Participants were paid 10 GBP to participate in the study. This study received ethical approval from the University College London's Office of Research Ethics (\#CPB/2013/015).

\section{Study 2}

A total of 121 undergraduate students ( 83 female, average age $=19.62$ years $)$ were recruited from the University of Waterloo undergraduate research pool between September 2018 and April 2019. Students participated in order to receive course credit in psychology courses. This study received ethical approval from the University of Waterloo's Office of Research Ethics (ORE \#21656, approved 22 August 2016).

\section{Apparatus}

HTC Vive

360-degree video with audio was presented to participants using an HTC Vive headset (Microsoft, Redmond WA). The device features a resolution of $2160 X 1200$ pixels with a field of view of 110 degrees. The device weighs approximately 555 grams and features three adjustable 
straps to ensure a tight and comfortable fit. The Vive contains on-board motion tracking so that scenes are updated corresponding to movements of the participant's head.

\section{Measures}

\section{Affect Measure}

The self-assessment manikin (SAM) (Figure 1) is a pictorial measure that assesses valence, arousal and dominance (sense of control). The SAM was developed in response to the semantic differential model (Mehrabian \& Russel, 1974), as it was determined the semantic differential model, at 18 9-point-scale questions, was too cumbersome to use to measure these constructs (Bradley \& Lang, 1994). The SAM was intended to measure responses to objects and events, which makes it an appropriate measure to examine the psychological impacts of a building, an object. Participants are instructed to mark the manikin that aligns with how they feel; if they could not choose a manikin, they could mark the space between. A paper pencil method was used for both the real world and virtual reality study.
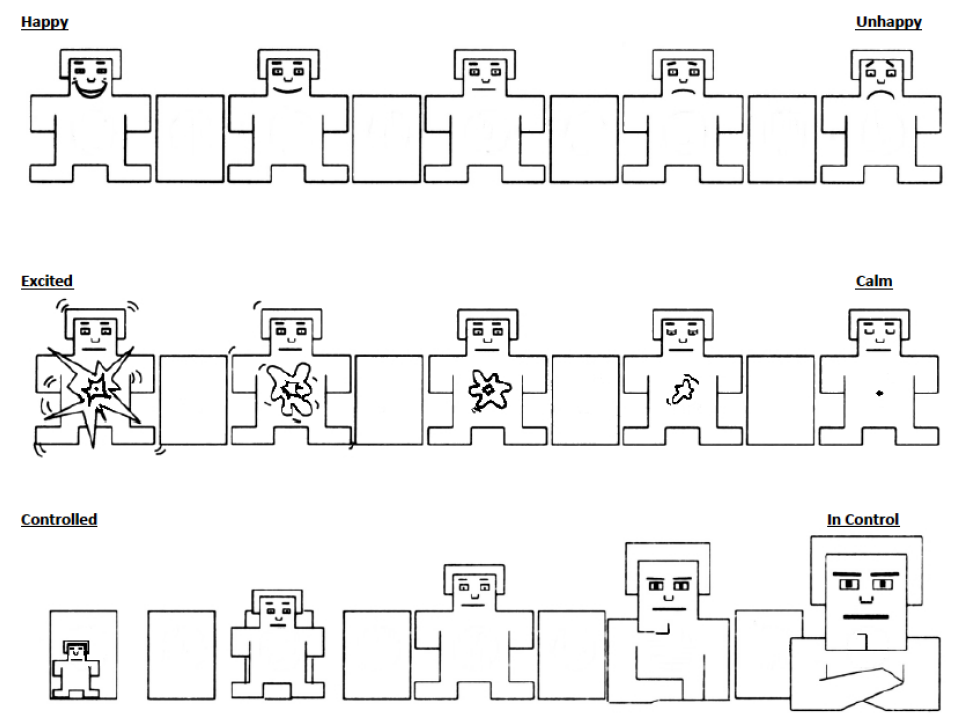

Figure 1. Self-Assessment Manikin measures of valence, arousal and sense of control (Bradley \& Lang, 1994). 


\section{Cognitive Appraisal}

We adapted the measures used by Asgarzadeh, Luska, Kogab and Hirate (2012) for this study. Participants were asked to answer the following questions in relation to the building they were placed in front of, on a scale of 1-7 (not at all - very): (1) How oppressed did you feel? (2) How disturbing was this feeling of oppressiveness? (3) How open did you perceive the setting to be? (4) How satisfied were you with the openness? and (5) How friendly was the setting? Physiological Measure

Electrodermal activity, also known as the galvanic skin response or skin conductance, is the measure of the rate of sweat gland response. It is generally considered to be a reliable index of sympathetic autonomic nervous system activity and indexes roughly with the concept of arousal. In this study, electrodermal activity was measured using a wearable device called the Empatica E4 (Empatica Inc., Milan, Italy) which measures electrodermal activity, heart rate, interbeat intervals, body temperature, and movement from the wrist. This device allows for a wireless measure of this data using Bluetooth and a smartphone application. The main variable of interest for this study was electrodermal activity. The skin conductance level values were averaged and divided into 1-minute intervals to produce five electrodermal activity values per participant.

Procedure

\section{Study 1}

This was a within-subjects design in which participants were taken to two locations in Central London (Figure 2), one where they were exposed to a high-rise building, and the other where they were exposed to a low-rise building. The locations were chosen through a systematic survey of Central London using Google Earth. Google Earth renders a 3D representation of the 
Earth, allowing us to scan the city for an ideal location. Clusters of high-rise buildings were examined, with particular attention paid to easy access to low-rise buildings. It was important to find two locations close together so that the journey between the buildings would not affect the ratings on the SAM, oppressiveness measures, or electrodermal activity. Time, and the process of walking long distances, or using an automobile to transport the participants could potentially affect results. Furthermore, we wanted to choose locations with minimal vehicular traffic, as the noise and visual commotion could also provide confounding effects. The high-rise building chosen (Figure 3a) was the Leadenhall Building (48 floors), located at 122 Leadenhall Street. The rear entrance backs onto a plaza on a cul-de-sac, on Undershaft Road. The cul-de-sac helped address the issue of vehicular traffic and noise, as it was a dead-end road. Across the cul-de-sac from the Leadenhall Building is the rear of St. Helen's Bishopsgate Church. It is a simple, red brick building ( 3 storeys). This was chosen to be the low-rise building (Figure 3b). The distance between the two locations was approximately 140 feet, which allowed for a quick transition between the two buildings. 8 participants were randomly assigned to view the high-rise building first, and 8 participants were randomly assigned to view the low-rise building first. Partial deception was involved; participants were informed that the purpose of the experiment was to compare responses from real-world exposure to virtual reality exposure, which was true, however, they were not informed that the other intention of the study was to measure affective, physiological and cognitive responses to high-rise buildings. The participants were fitted with the Empatica E4 device on their non-dominant hand. They were then brought in front of the building and were instructed to observe the building for five minutes. After five minutes, they were provided with a paper-pencil SAM and cognitive appraisal questionnaire. When those two questionnaires were completed, they were taken to the other building and the same procedure 
was implemented. A graphical representation of the experimental procedure can be viewed in

Figure 4.

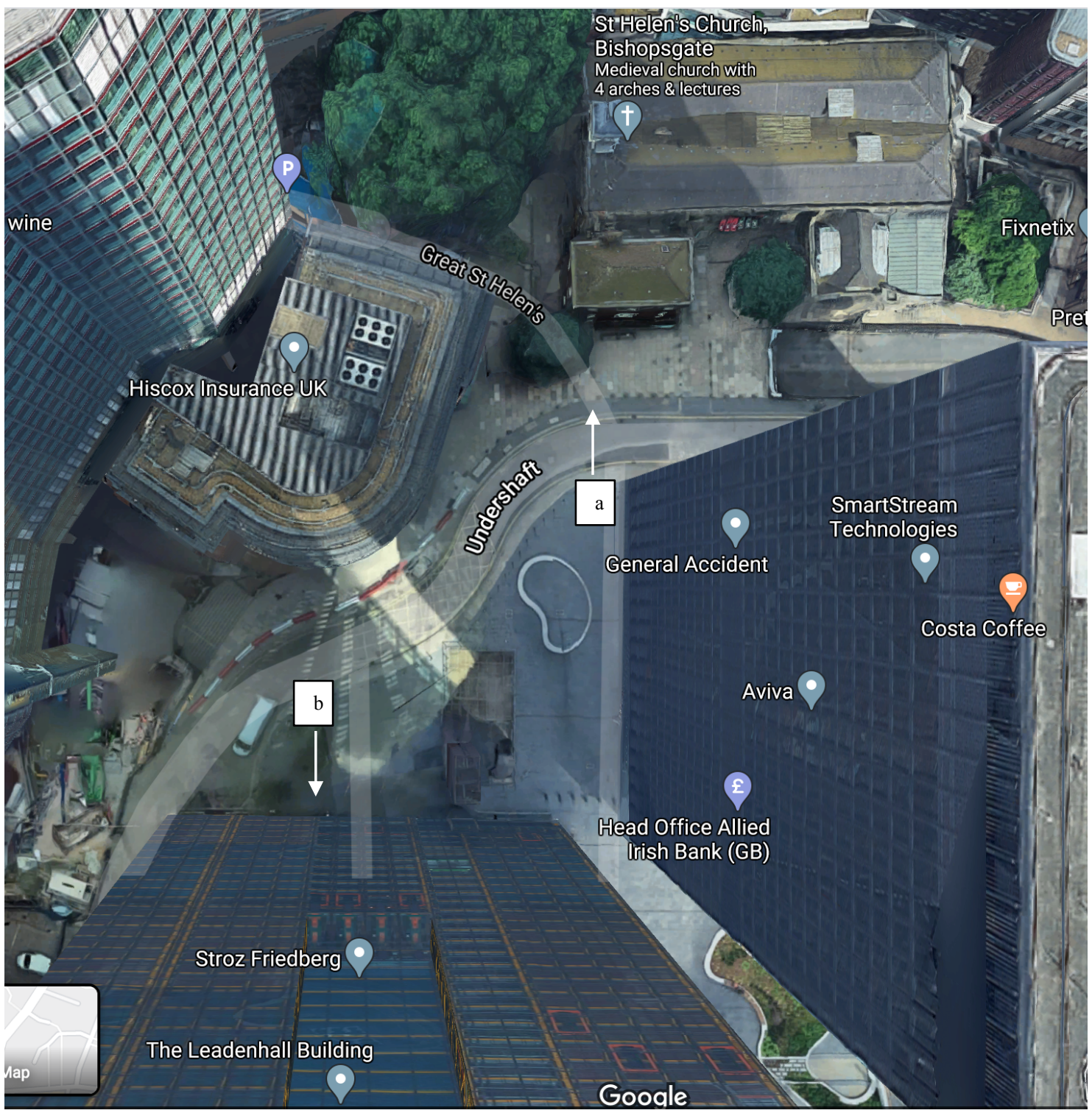

Figure 2. Aerial map of study location. (a) low-rise building observation point. (b) high-rise building observation point. 


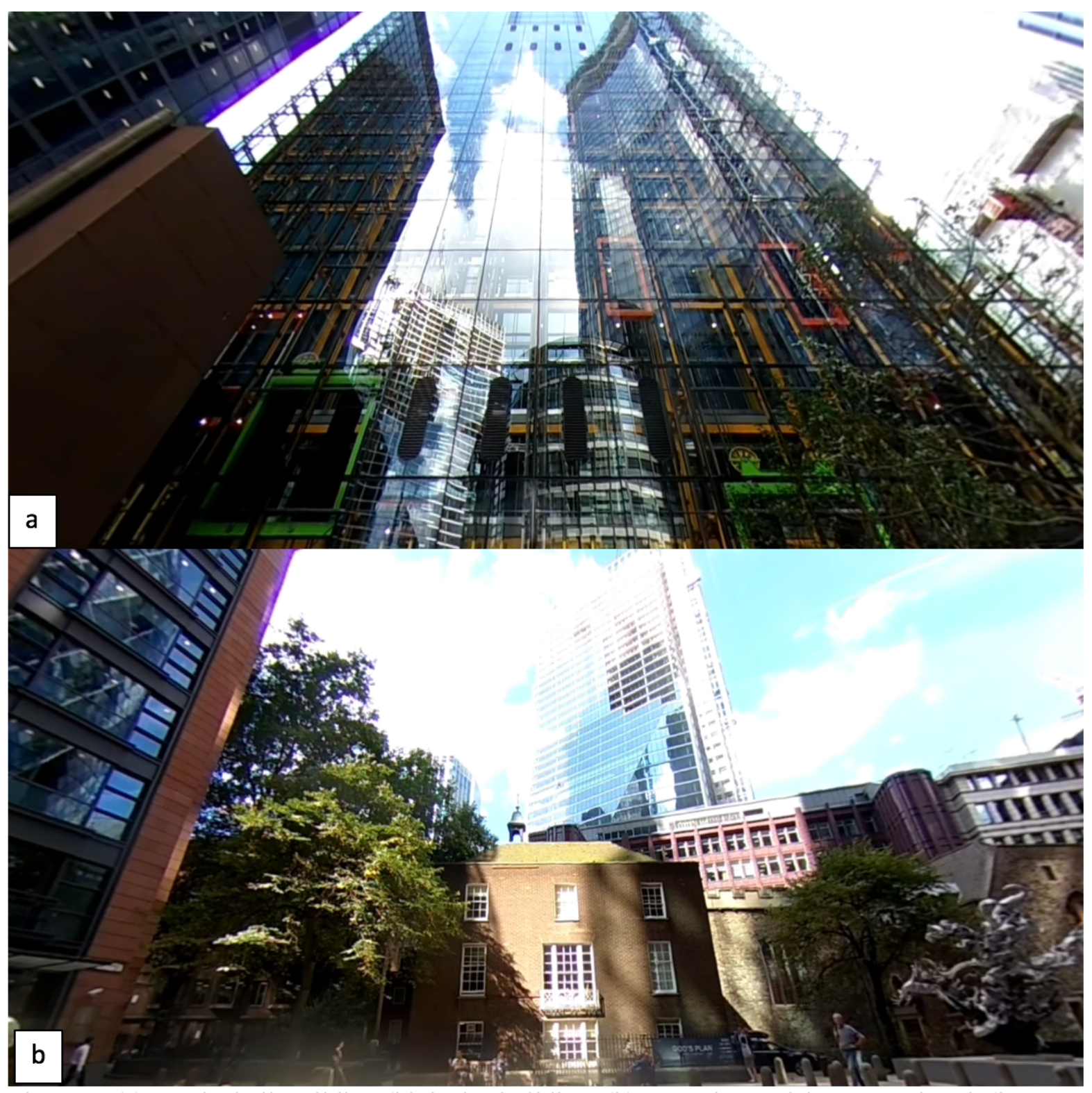

Figure 3. (a) Leadenhall Building (high-rise building). (b) St. Helen's Bishopgate Church (lowrise building)

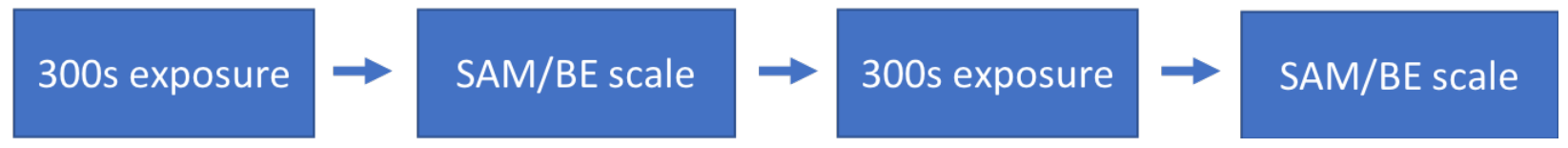

Figure 4. Experimental procedure for both Study 1 and Study 2 


\section{Study 2}

This was a within-subjects design where, using immersive virtual reality, participants were exposed to 360-degree video of the low-rise and high-rise buildings from Study 1 . The 360degree video was captured using a Ricoh Theta V camera; the camera was placed at the exact locations where participants were asked to stand in study 1 . The same partial deception used for study 1 was used for study 2. Participants were fitted with the Empatica E4 bracelet. They were then fitted with the HTC Vive and exposed to a five minute 360-degree video clip of one of the buildings and were instructed to observe the building. Following the five-minute exposure, the HTC Vive headset was removed and participants were asked to complete a paper-pencil SAM and cognitive appraisal questionnaire. Following completion, they were then exposed to the other building, and the same procedure was used. Participants were randomly assigned to the order of the conditions, and counterbalancing was ensured. A graphical representation of the experimental procedure can be viewed in Figure 4.

\section{Results and Discussion}

\section{Study 1}

Four sets of analyses were performed. EDA values from the 5-minute exposure were averaged and divided into 1-minute intervals to produce five electrodermal activity values per participant; a one-way repeated measures ANOVA was performed on the 1-minute intervals. We found no effect of building height on electrodermal activity. A doubly multivariate one-way repeated measures was run on openness and openness satisfaction. There was a statistically significant effect of building height on openness (Figure 5), $F(1,15)=7.74, p=.014$; Wilk's $\Lambda=$ 0.63 , partial $\eta 2=.34$. There was no effect of building height on openness satisfaction. A doubly multivariate one-way repeated measures ANOVA was also run on the SAM measures of valence, 
arousal and dominance. There was a statistically significant effect of building height on valence (Figure 6), $F(1,15)=9.00, p=.009$; Wilk's $\Lambda=0.54$, partial $\eta 2=.38$. Lastly, a doubly multivariate one-way repeated measures was run on the qualitative measures of oppressiveness, disturbingness, friendliness. There were no effects of building height on these measures.

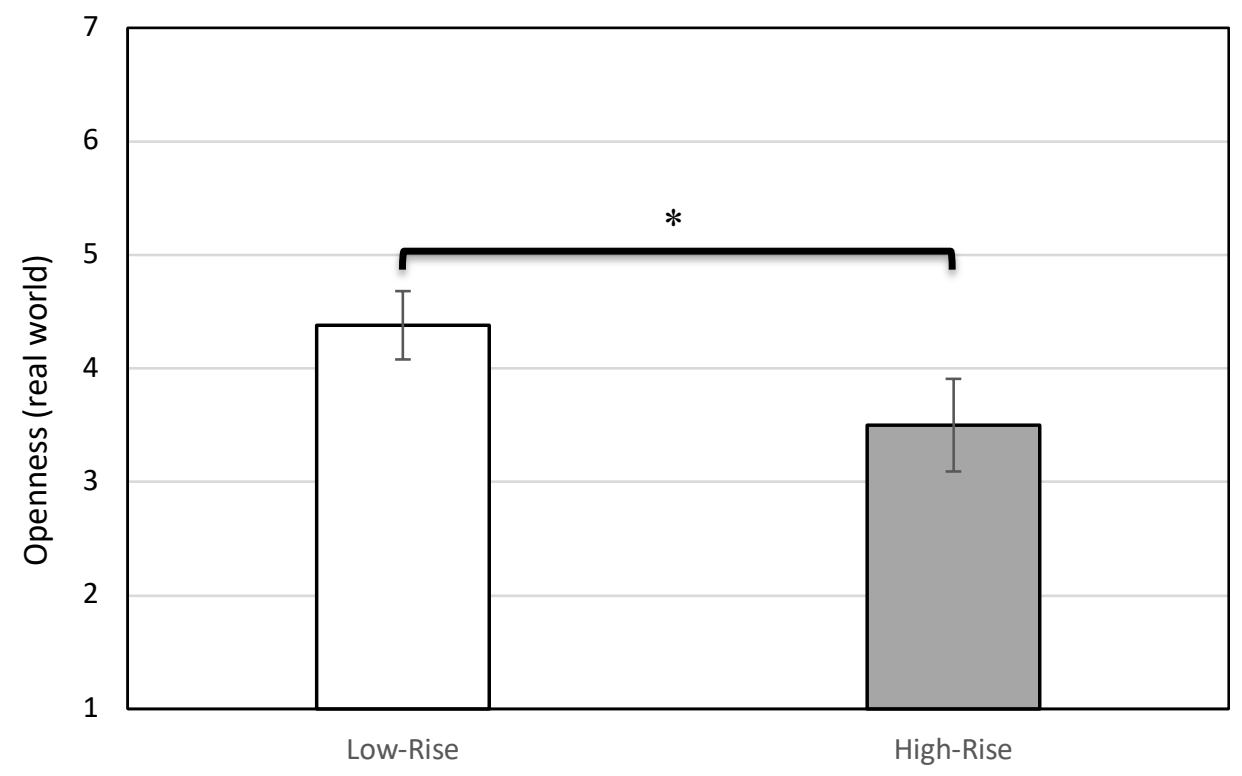

Figure 5. Influence of building height on openness ratings in the real-world test. $(9=$ most open) Significant difference found. Error bars represent \pm 1 SEM. ${ }^{*} p<.05$ 


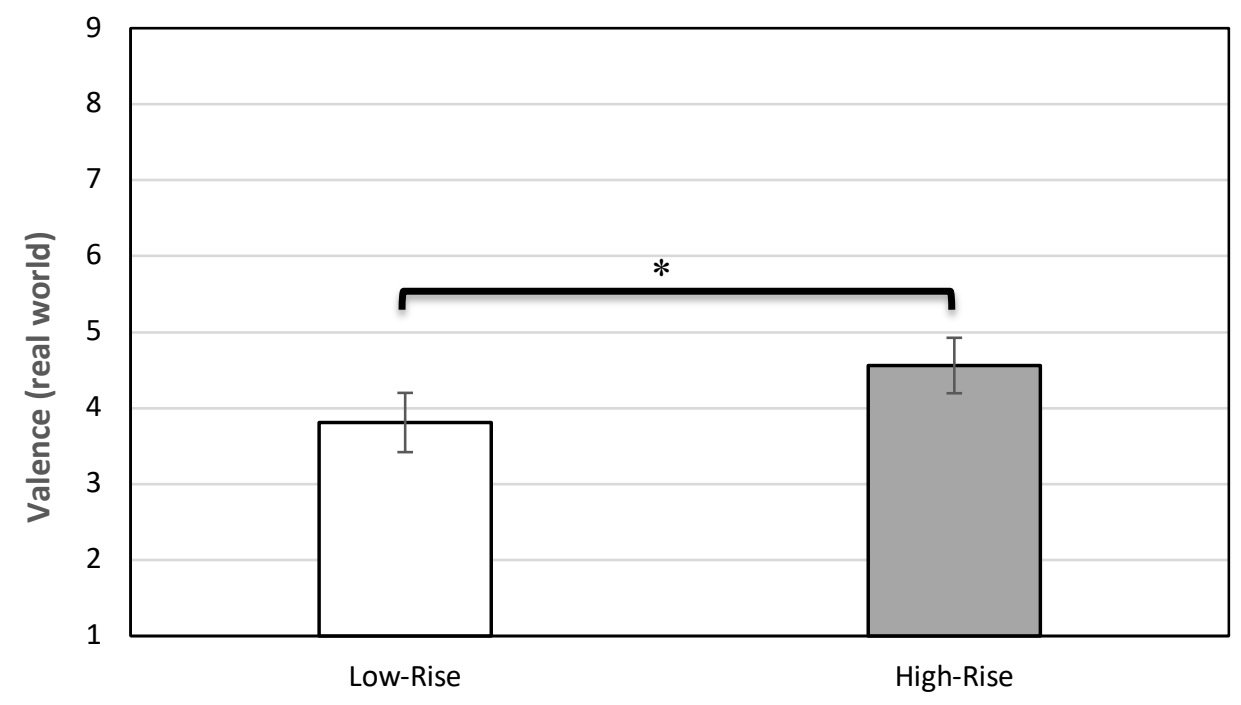

Figure 6. Influence of building height on valence ratings in the real-world test. $(9=$ most unhappy) Significant difference found. Error bars represent \pm 1 SEM. ${ }^{*} p<.05$

\section{Study 2}

The same analyses that were run in study 1 were run in study 2 . EDA values from the 5minute exposure were averaged and divided into 1-minute intervals to produce five electrodermal activity values per participant; a one-way repeated measures ANOVA was performed on the 1-minute intervals. We found no effect of building height on EDA. A doubly multivariate one-way repeated measures ANOVA was run on openness and openness satisfaction. There was a statistically significant effect of building height on openness (Figure 7), $F(1,119)=32.88, p<.001$; Wilk's $\Lambda=0.76$, partial $\eta 2=.22$, and openness satisfaction (Figure 8), $F(1,119)=34.37, p<.001$; Wilk's $\Lambda=0.76$, partial $\eta 2=.22$. A doubly multivariate one-way repeated measures ANOVA was also run on the SAM measures of valence, arousal and dominance. There was a statistically significant effect of building height on valence (Figure 9), $F(1,119)=14.12, p<.001 ;$ Wilk's $\Lambda=0.88$, partial $\eta 2=.11$, and dominance (Figure 10$), F(1$, 
$119)=6.35, p<.001 ;$ Wilk's $\Lambda=0.88$, partial $\eta 2=.05$. Lastly, a doubly multivariate one-way repeated measures ANOVA was run on the qualitative measures of oppressiveness, disturbingness, friendliness. There was a statistically significant effect of building height on friendliness (Figure 11), $F(1,119)=34.90, p<.001 ;$ Wilk's $\Lambda=0.75$, partial $\eta 2=.23$.

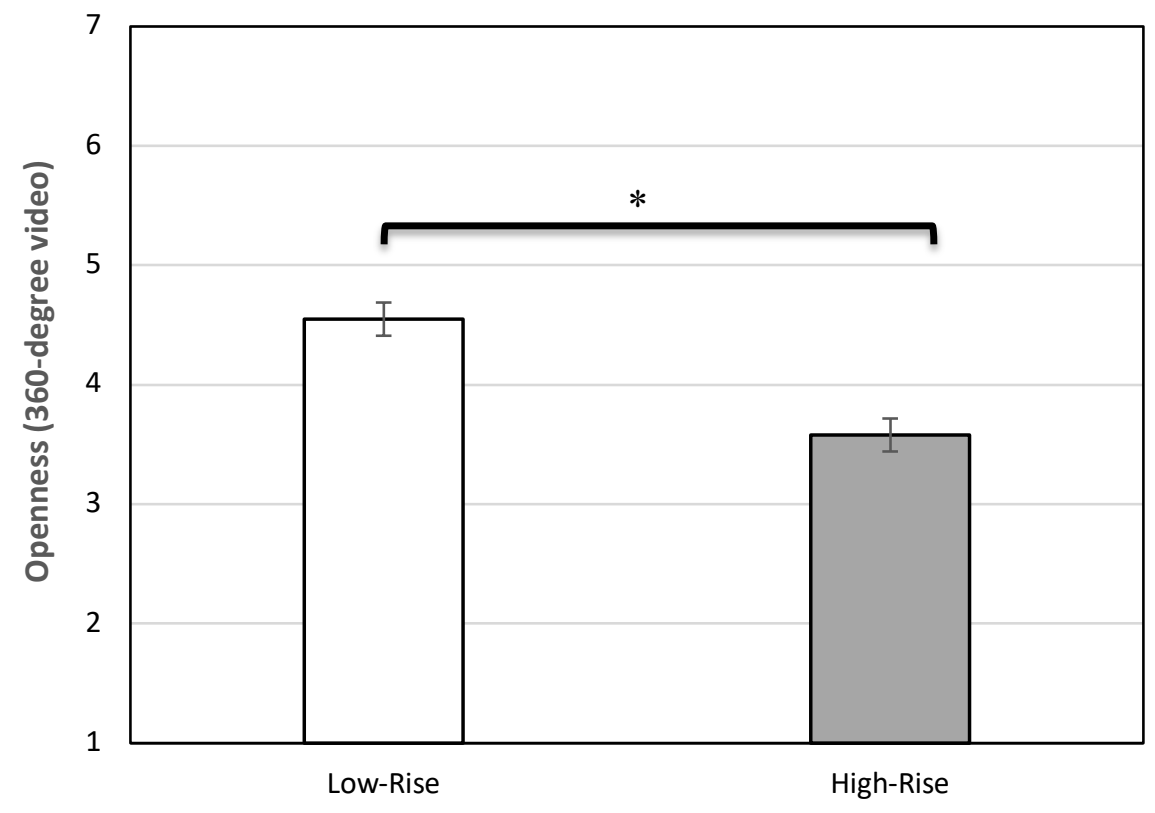

Figure 7. Influence of building height on valence ratings in the real-world test. $(9=$ most unhappy) Significant difference found. Error bars represent \pm 1 SEM. ${ }^{*} p<.05$ 


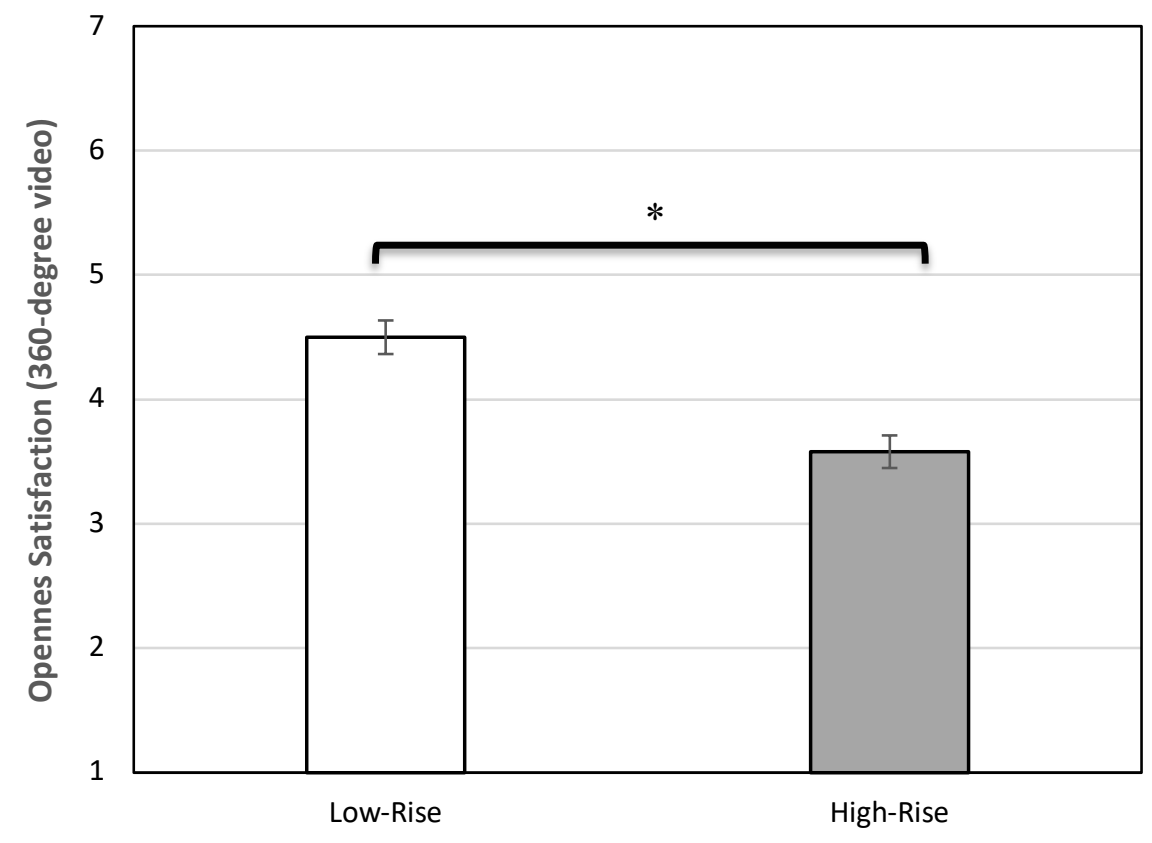

Figure 8. Influence of building height on openness satisfaction ratings in the virtual reality test. ( $9=$ most satisfied) Significant difference found. Error bars represent \pm 1 SEM. $* p<.05$

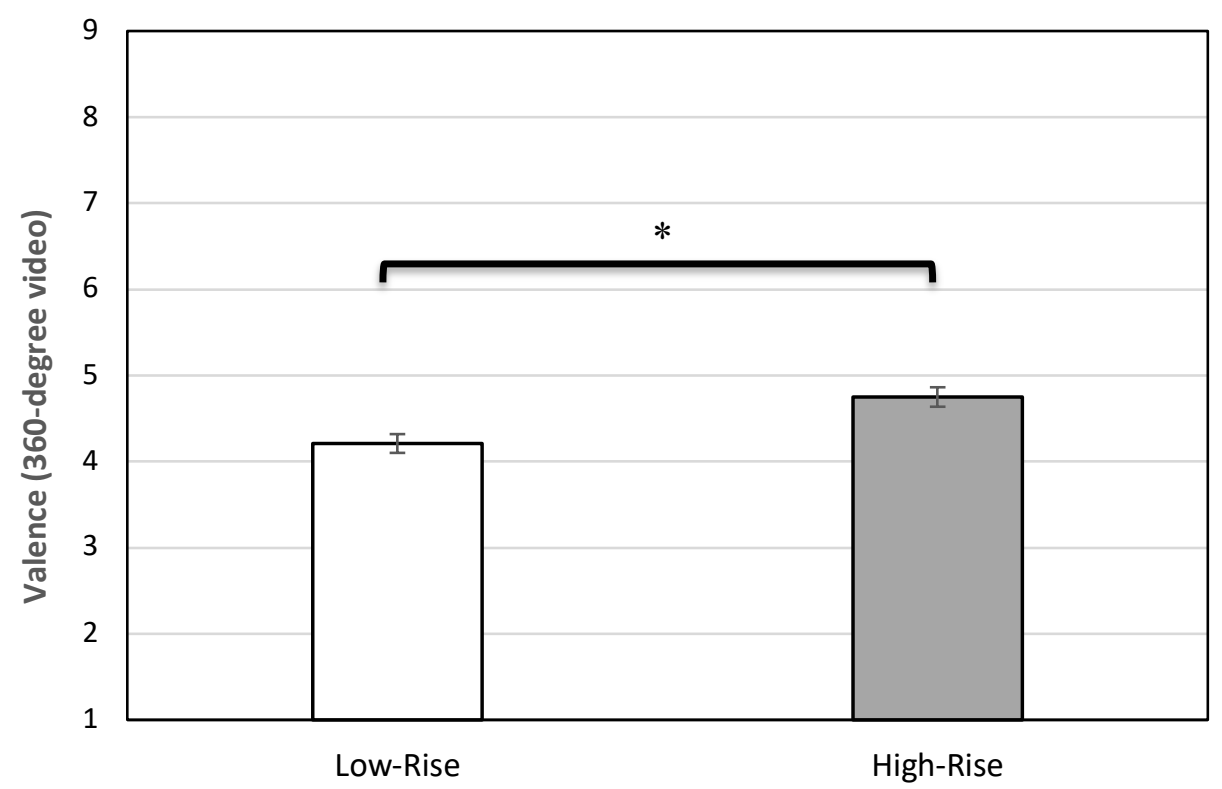

Figure 9. Influence of building height on valence ratings in the virtual reality test. $(9=$ least happy) Significant difference found. Error bars represent \pm 1 SEM. ${ }^{*} p<.05$ 


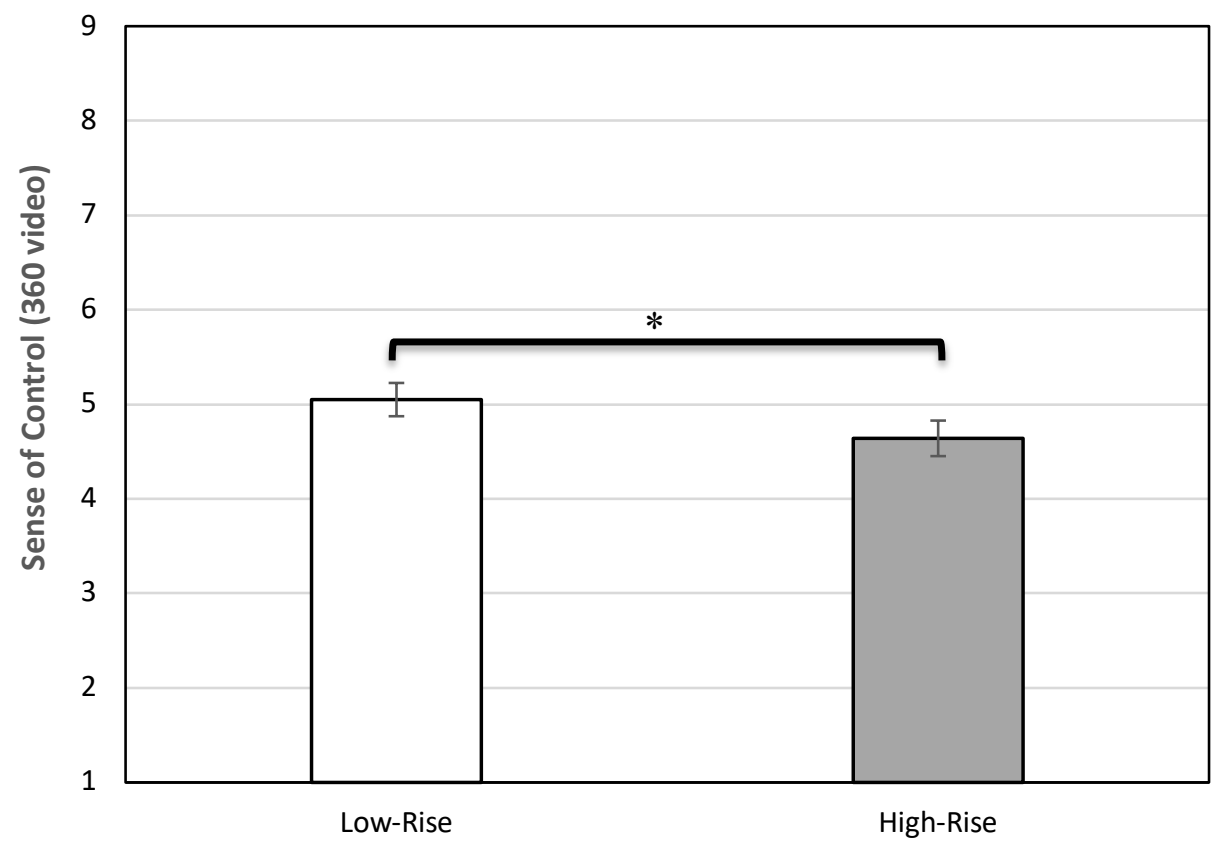

Figure 10. Influence of building height on dominance ratings in the virtual reality test. $(9=$ most in control) Significant difference found. Error bars represent \pm 1 SEM. $* p<.05$

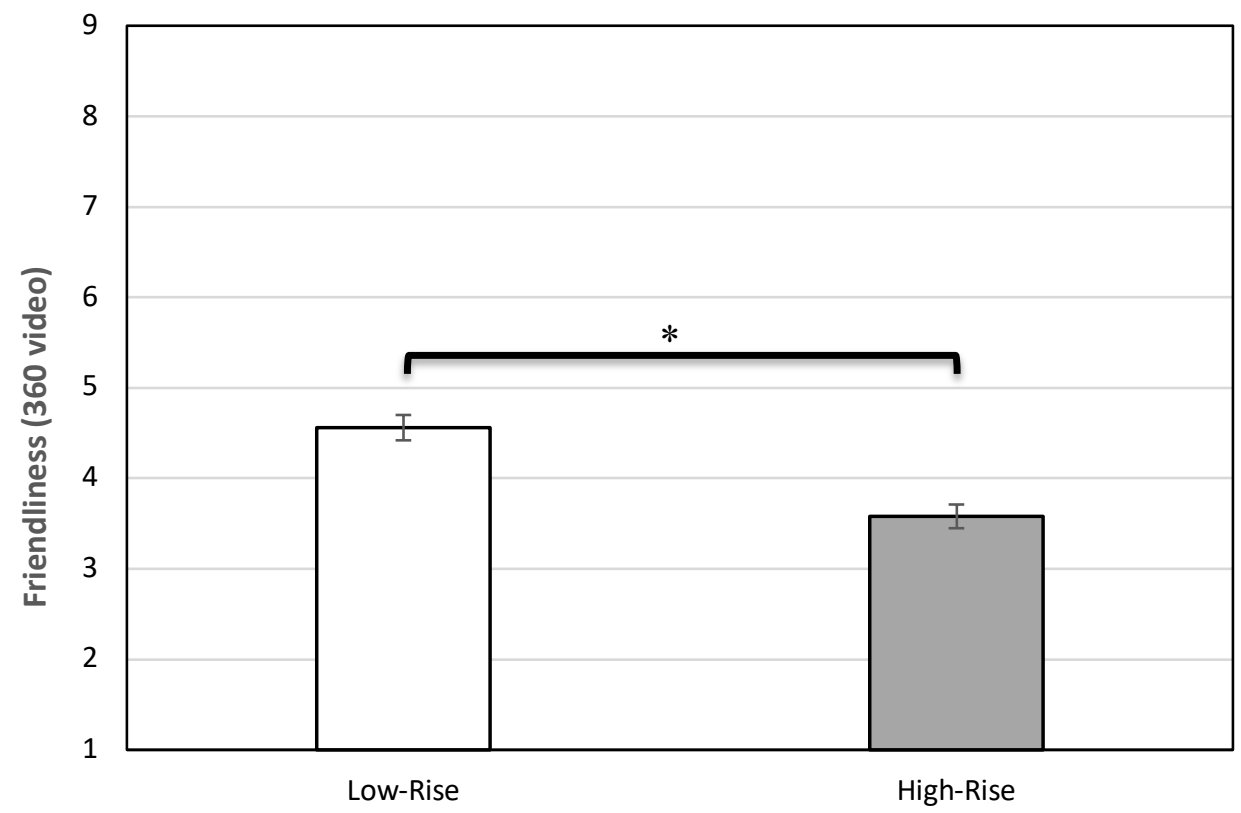

Figure 11. Influence of building height on friendliness ratings in the virtual reality test. $(9=$ most friendly) Significant difference found. Error bars represent \pm 1 SEM. ${ }^{*} p<.05$ 


\begin{tabular}{|c|c|c|c|c|c|c|c|c|}
\hline Variables & $\frac{1}{(\text { Val })}$ & $\stackrel{2}{(\text { Aro })}$ & $\stackrel{3}{(\operatorname{Sen})}$ & $(\stackrel{4}{(O p p)})$ & $\stackrel{5}{(\mathrm{Dis})}$ & $(\underline{6})$ & $\stackrel{7}{\text { (Sat) }}$ & $\underline{8}$ \\
\hline 1. Valence & - & & & & & & & \\
\hline 2. Arousal & -.02 & - & & & & & & \\
\hline 3. Sense of Control & $-.18^{*}$ & .005 & - & & & & & \\
\hline 4. Oppressiveness & $.17 *$ & $-.36 * *$ & $-.29 * *$ & - & & & & \\
\hline 5. Disturbingness & $.30 * *$ & $-.28 * *$ & $-.24 * *$ & $.72 * *$ & - & & & \\
\hline $\begin{array}{l}\text { 6. Openness } \\
\text { 7. Openness }\end{array}$ & $-.30 * *$ & -.07 & $.26^{* *}$ & $-.22 * *$ & $-.20 * *$ & - & & \\
\hline Satisfaction & $-.39 * *$ & .01 & $.24^{* *}$ & $-.25^{* *}$ & $-.29 * *$ & $.73^{* *}$ & - & \\
\hline 8. Friendliness & $-.31 * *$ & .16 & $.41 * *$ & $-.27 * *$ & $-.30 * *$ & $.41 * *$ & $.48^{* *}$ & - \\
\hline
\end{tabular}

Table 1. Correlation matrix displaying correlations between subjective measures. ${ }^{* *} \mathrm{p}<.01,{ }^{*} \mathrm{p}$ $<0.05$.

\section{Correlations}

A bivariate correlation analysis (Table 1) revealed moderate correlations between negative affect, our primary variable of interest, and disturbingess. There were also moderate negative correlations between negative affect and openness, openness satisfaction and friendliness. Openness, the only variable that pertained to the spatial dimensions of the environments, was moderately correlated with sense of control and friendliness and negatively correlated with oppressiveness and disturbingness.

\section{Comparing Study 1 and Study 2}

In addition to understanding how building height influenced electrodermal activity, openness, openness satisfaction, valence, arousal, dominance, oppressiveness, disturbingness and friendliness, this study was also designed to assess whether 360-degree video displayed in immersive virtual reality could be used as an approximation of the real world. To do this, we ran one-way ANOVAs comparing each of the variables previously mentioned between real world and virtual reality conditions. There were no statistically significant differences for any of the 
measures. Figures 12 and 13 compare the similar results from the real world and virtual reality study.

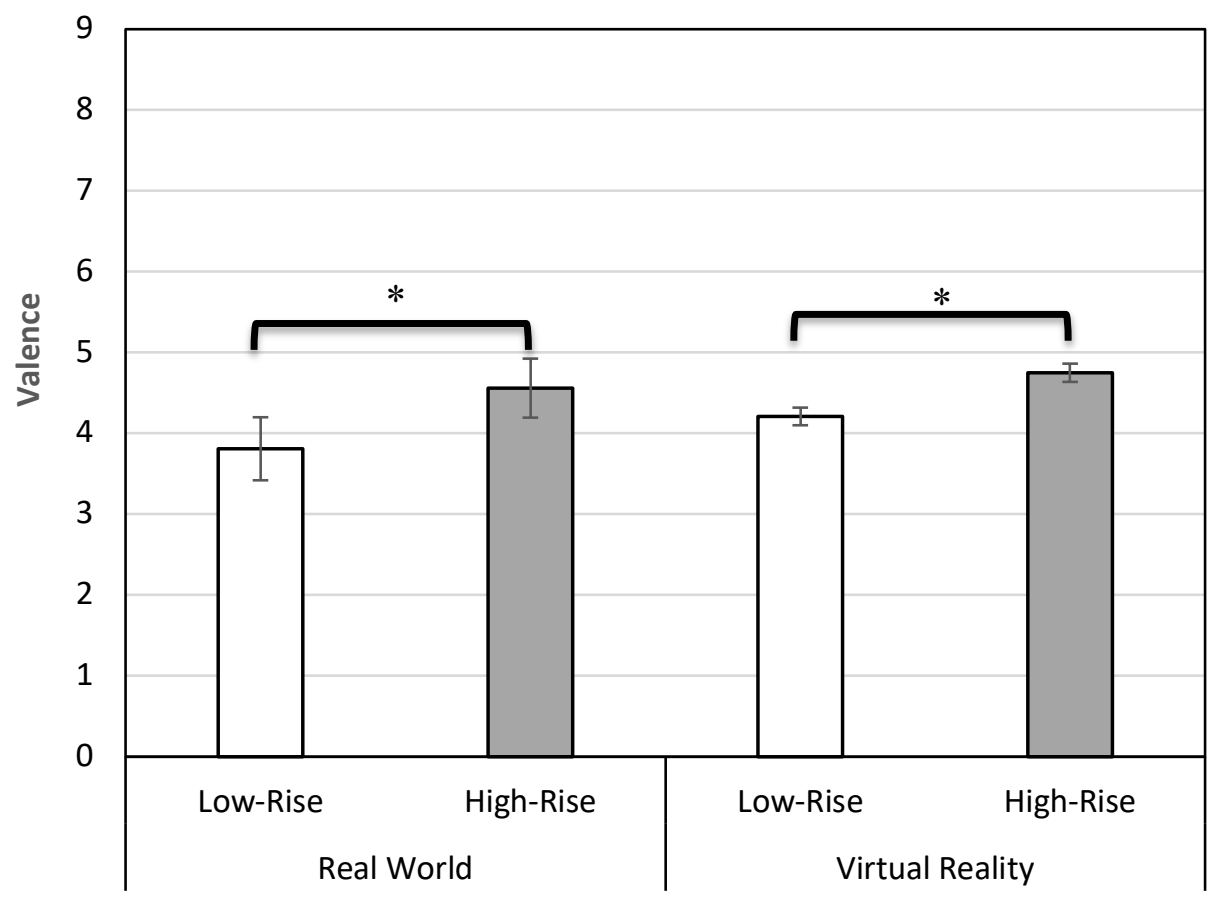

Figure 12. Influence of building height on valence ratings in the real world and virtual reality test. $(9=$ least happy) Significant difference found. Error bars represent \pm 1 SEM. $* p<.05$ 


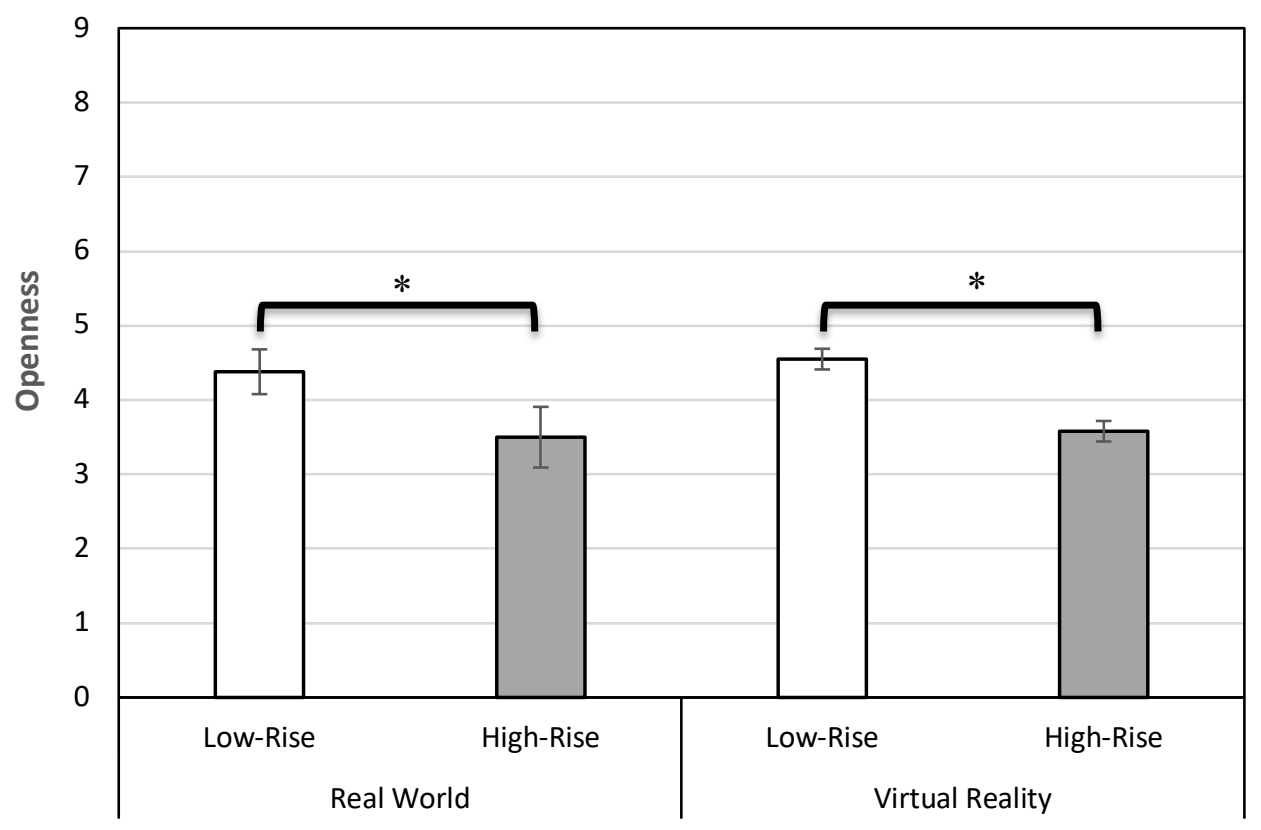

Figure 13. Influence of building height on openness ratings in the real world and virtual reality test. $(9=$ most open $)$ Significant difference found. Error bars represent \pm 1 SEM. $* p<.05$

\section{Discussion}

Our study demonstrated that people found high-rise buildings, as compared to low-rise buildings, in a real-world setting, to be associated with lower ratings of openness and friendliness and higher ratings of negative affect. We found similar effects in virtual reality, through use of an HMD and 360-degree video. The 360-degree video study allowed for a larger sample size and helped confirm our hypothesis that high-rise buildings are associated with lower openness satisfaction and lower sense of control.

Here, we used a naturalistic scenario in a real city to compare building height. For London this meant that very tall buildings would inevitably be made of glass and steel (if representative). Whereas low-rise buildings would likely be constructed from brick. These two materials and the historical way they have been used in the architecture may play a role in 
driving responses we observed. This will be important to explore in future research in other settings beyond London UK. For brevity, here we discuss the impact of high vs low rise with respect to this core quality, but it is important to acknowledge that this distinction comes with it a change in materials and architecture. In doing ecologically valid research, we required a site where both a low-rise and high-rise building was accessible in close proximity.

The low-rise building setting was rated as being more open and that (in our sample with video) participants were more satisfied with the openness, which aligns with previous research (Asgarzadeh, Luska, Kogab and Hirate, 2012; Asgarzadeh et al. 2014; Zarghami et al. 2019). In their work on environmental preferences, Kaplan, Kaplan \& Brown (1989) identify four domains of predictors for scene preference: land form (i.e slope of land), land cover (i.e forestation), informational variable (i.e complexity), and perception-based variables (i.e openness). Of the four domains, perception-based variables, namely openness, had the strongest predictive power for scene preference (Kaplan \& Kaplan, 1989). People prefer an open view, as it allows them to assess their environment more easily and understand the affordances within it (Kaplan \& Kaplan, 1989). Buildings populated with high-rise buildings possibly impede one's ability to scan their environments. It has been argued that spatial enclosure elicits a threat response as measured by neural activity (Vartanian et al., 2015). While Vartanian et al's study involved interior design of rooms, it can be extended to the urban environment; Ewing and Handy (2009) state that “buildings become the 'walls' of the outdoor room” ( $p$ 74). In his book, Exterior Design of Architecture, Asihara (1970) explores the relationship between building height and the space between buildings, suggesting that when the height of buildings exceeds the space between them that "we feel a sense of being closed in that builds up to a kind of claustrophobia." (p 43). In their study on the effects of oppressiveness of high-rise buildings, Asgarzadeh, Luska, Kogab 
and Hirate (2012), using pictures, demonstrated that high-rise buildings were associated with lower openness and higher opppressivenes ratings. They describe oppressiveness as a being related to an invasion of personal space. Accordingly, this invasion of space could in fact be connected to how enclosure causes a sense of impediment of movement. Stamps and Smith (2002) state "it is possible that a space could give the impression of enclosure without limiting what can be seen.” These findings also aligned with the work of Stamps (2005), who, through exposing research participants to pictures of urban built environments, found building height was positively correlated with ratings of enclosure. Our findings indicate that openness varies with building height, and that there may be implications on an individual's affective state as a result of these spatial parameters that provoke a sense of inescapability.

In the Probabilistic Model of Aesthetic Response, Nasar (1994) suggests that aesthetic responses to buildings, specifically, involve both a cognitive and an affective component, indicating scale as a formal aesthetic attribute. While the existing literature measured enclosure (Lindal \& Hartig, 2013; Stamps, 2010; Stamps \& Smith, 2002), here we also measured the impact of being in the presence of high-rise buildings on an individual's emotional state. To our knowledge, our study is the first that uses an established psychological assessment to measure affective responses to high-rise buildings. Through use of the SAM, we were able to measure how building height influenced negative affect and found a significant effect of building height on affect in both the real world and the virtual setting. This negative affect could potentially lead to a longer-term impact on physiology through stress responses. A study by Beil and Hanes (2013) comparing very natural and very built environments, found environments with the most buildings to be associated with the highest concentration of salivary amylase, a hormone associated with stress. Campbell (1981) proposes ambient stressors have 5 main characteristics: 
they are perceptible, chronic, non-urgent, intractible and have a negative tone. The word "ambient" is used to highlight the fact that these stressors are often in the background and not at the forefront of our awareness. Ambient stressors can, over the long term, have negative impacts on wellbeing (Campbell,1981). This suggests urban settings densely populated by high-rise buildings could be considered to be ambient stressors which could have negative effects on an individual's emotional state. Results from our 360-degree video study also demonstrate the participants rated themselves as having a lower sense of self control when exposed to the highrise building. This aligns with work done by Joye \& DeWitte (2012), who suggest that high-rise buildings evoke negative awe. They found that participants felt smaller when exposed to taller buildings, as compared to being exposed to smaller buildings. Evans \& McCoy (1998) suggest that largeness of buildings is associated with institutionalization, which can cause feelings of powerlessness. Furthermore, a sense of control may also be tied to the visual permeability of the environment (Stamps, 2005); high-rise buildings can obstruct an individual's ability to survey the surrounding area. Participants also found the low building setting friendlier, suggesting that this environment was more approachable and pleasant. All of our findings, taken into concert, suggest that the high-rise building setting was less desirable than the low-rise building setting.

Our study also has methodological implications, confirming that 360-degree video viewed within an HMD can be used as a viable alternative to real world exposure. A study by Yuhan, Lange \& Thwaites (2015) found that 360-degree panoramic photos were more effective in allowing participants to appraise a landscape than typical 60-degree photos. Furthermore, Higuera-Trujillo, Moldonado and Millan (2017) examined the validity of the use of photos, panoramic photos and virtual environments to simulate real environments. They found that panoramic photos were the most realistic, as measured by psychological responses, and 
virtual reality environments were the most realistic, as measured by physiological responses. Our study utilized 360-degree videos, which combines elements of both panoramic photos and virtual reality; 360-degree videos are essentially panoramic videos viewed within a virtual environment, and so they address both the psychological and physiological components of emulating the experience of the built environment. This approach aligns with the environmental psychology school of transactionalism, which recognizes the complexity of studying the dynamic experience of an individual in an environment.

There are many challenges associated with studying the psychological experience of urban environments. Conducting field research in the city can require extensive organizational efforts and planning. These extra efforts can reduce the number of participants that can be tested. More importantly, each participant experiences a different condition, where the sound, weather, and number of people present can vary. The confounds within this methodology must be acknowledged and addressed in this field of research; the 360-degree video method offers a potential solution. It addresses the complexity of scheduling and meeting participants in the field and allows testing to be done in the lab; it also ensures participants are exposed to the same visual and auditory conditions and increases confidence in inferences made on how the built environment influences an individual's affect.

\section{Limitations and future directions}

One surprising finding of this study is that neither the real world or the 360-degree video study yielded significant effects of building height on oppressiveness. Previous studies which found effects of building height on ratings oppressiveness recruited architectural students as participants; there is a possibility that architectural students are more familiar with the concept of oppressiveness, which may be more of an abstract construct for psychology students to grasp; 
some study participants in previous studies were unsure about the meaning of the word (Asgarzadeh, Luska, Kogab and Hirate, 2012; Asgarzadeh et al. 2014; Zarghami et al. 2019). We did, however, observe significant effects of building height on ratings of openness. These findings may indicate that openness is a more concrete and understandable construct to measure. Alternatively, it may be that the sense of enclosure in the space is evoked more rapidly than the sense that the environment is oppressive, leading to openness ratings differentiating the two settings within the time period we conducted our experiment; temporal elements of exposure in environmental psychological research should be considered. We also did not obtain any significant results of EDA. We suspect this is due to the Empatica E4 recording EDA from the wrist, as opposed to the palm, where there are much higher densities of eccrine sweat glands. Unfortunately, most wearable devices that measure EDA measure from the wrist, and the E4 was the only wearable device available to use for this research. While the density of eccrine sweat glands varies per person, it is understood that the highest density of eccrine sweat glands in the human body are at the palms, soles of the feet, arm pits, and forehead (Saga, 2002). In a study examining the reliability of EDA recording sites, Payne, Schell and Dawson (2016) found that the wrist had the lowest responsiveness, while the fingers, considered to be the gold standard for EDA recording, had the highest responsiveness; $31 \%$ of responses evoked at palmar sites were not evoked at the wrist. Furthermore, EDA readings taken at wrist sites were found to be moderately correlated with EDA readings taken at the palm (van Dooren, de Vries \& Janssen, 2012). Another issue with recording at the wrist is the confound of added thermoregulatory sweat gland activity. Payne, Schell and Dawson (2016) state, "locations such as the wrist, where sweat glands respond to temperature as well as to psychological states, may be confounded in 
terms of causality of SCRs, given that in ambulatory SC recording, sweat gland activation due to temperature changes and physical exertion is likely." (p. 1088).

This study is also limited in the demographic variables examined. Future research should examine how one's upbringing and cultural background influences perceptions of the urban environment. A study by Coutrot et al (2020) found that in a sample of 3.9 million participants growing up in cities of countries with predominately 'griddy' city centres were worse at navigating compared to their fellow citizens who had grown up in rural or mixed backgrounds. Thus, it seems possible that perceptions of the environment and affect driven by it may vary similar to the navigation through it. Furthermore, an fMRI study by Lederbogen et al (2011) found that people who grow up in urban environments have greater activation in brain regions associated with emotional regulation (e.g. amygdala and anterior cingulate cortex). Thus, different methods and approaches are beginning to shed new light on the impact urban environments and the features within them have on our cognition and emotional responses. Such studies suggest the need for a deeper examination into how an individual's background and life experiences can inform how they perceive and engage with the urban built environment.

Nasar (1994) recommends that attention should be paid to the visual character of a building for the sake of the public good. Our findings suggest that building height can have a negative impact on an individual's emotional state. Mayor of London, Sadiq Khan, has directed individual boroughs in London, which is seeing an upswell of high-rise buildings across the city, to decide whether how tall buildings should be and to consider if the spatial context and character is suitable to them (City of London, 2020). It is a compromise between character and housing utility in a city that is faced with a massive shortage in housing (The Guardian, 2020). 
The following is an excerpt from the City of London's Draft New London Plan (2020) on highrise buildings that suggests the following is considered:

"Immediate views [of high-rise buildings] from the surrounding streets [need to be considered] - attention should be paid to the base of the building. It should have a direct relationship with the street, maintaining the pedestrian scale, character and vitality of the street. Where the edges of the site are adjacent to buildings of significantly lower height or parks and other open spaces, there should be an appropriate transition in scale between the tall building and its surrounding context to protect amenity or privacy."

The plan further states that, "buildings near the River Thames, particularly in the Thames Policy Area, should not contribute to a canyon effect along the river which encloses the open aspect of the river." This policy clearly acknowledges the visual impact of high-rise buildings on the street level and nearby open green and blue spaces. The New London Authority (2020), a non-profit organization that focuses on the effects of the built environment, suggests that high-rise buildings should be "good neighbours visually" (p. 50). It is encouraging to see this focus on the atmospheric stressors that can be caused by exposure to high-rise buildings. The findings from this study, while preliminary, can provide empirical psychological support to policies that stand to inform the visual experience of London, and other cities facing similar issues. That the City of London, a "world" city, is directly addressing the elements examined in study, should signal that these research questions are of practical use, and have implications beyond the laboratory. As cities continue to densify, it is important that a psychological lens is applied to the process of urbanization. 


\section{Conclusion}

Our research joins a growing body of work that demonstrates that urban environments shape our psychological state (Ellard, 2015; Goldhagen, 2017; Montgomery, 2013). The methodology used to examine the psychological impacts of urban design in the lab setting has evolved over the years, from having participants appraise photos (Kaplan \& Kaplan, 1979), to having research participants imagine themselves in different settings (Thiel, Harrison \& Alden, 1986), to taking people out into the real world (Asgarzadeh et al, 2014; Negami et al, 2019), to displaying 2D images on a large, angled screen (Asgarzadeh, Luska, Kogab and Hirate, 2012; Zarghami et al. 2019), to our current study where we both took people out in the real world and seperately placed them in immersive 360-degree video environments using a virtual reality headset with stereo audio sounds and used psychological measures to assess their experience.

Our findings are two-fold. First, they suggest that exposure to high-rise buildings can have a negative impact on affect. This has implications on the conversation on the urban design of our cities. Second, we show the value of using immersive 360-degree video for testing spatial experiences and validating it in comparison to a real-world experience. This study provides a foundation for future research in which 360-degree videos could be edited to manipulate the stimuli and may provide important means to control a range of variables and probe experience further. Thus, this research not only provides insight into the psychological impacts of urban design, but also helps advance the methods used to obtain these understandings. 


\section{References}

Ali, M. M., \& Al-Kodmany, K. (2012). Tall buildings and Urban habitat of the 21st century: A global perspective. Buildings, 2(4), 384-423. https://doi.org/10.3390/buildings2040384

Appert, M., \& Montes, C. (2015). Skyscrapers and the redrawing of the London skyline: A case of territorialisation through landscape control. Articulo - Journal of Urban Research, 2015(Spec. Issue 7). https://doi.org/10.4000/articulo.2784

Asgarzadeh, M., Koga, T., Hirate, K., Farvid, M., \& Lusk, A. (2014). Investigating oppressiveness and spaciousness in relation to building, trees, sky and ground surface: A study in Tokyo. Landscape and Urban Planning, 131, 36-41. https://doi.org/10.1016/j.landurbplan.2014.07.011

Asgarzadeh, M., Lusk, A., Koga, T., \& Hirate, K. (2012). Measuring oppressiveness of streetscapes. Landscape and Urban Planning, 107(1), 1-11. https://doi.org/10.1016/j.landurbplan.2012.04.001

Asihara, Y. (1981). Exterior design in architecture. Van Nostrand Reinhold.

Beil, K., \& Hanes, D. (2013). The influence of urban natural and built environments on physiological and psychological measures of stress - A pilot study. International Journal of Environmental Research and Public Health, 10(4), 1250-1267. https://doi.org/10.3390/ijerph10041250

Bokharaei, S., \& Nasar, J. L. (2016). Perceived Spaciousness and Preference in Sequential Experience. Human Factors, 58(7), 1069-1081. https://doi.org/10.1177/0018720816650068 
Bradley, M. M., \& Lang, P. J. (1994). Measuring emotion: The self-assessment manikin and the semantic differential. Journal of Behavior Therapy and Experimental Psychiatry, 25(1), 4959. https://doi.org/10.1016/0005-7916(94)90063-9

Buhmann, E., \& Ervin, S. (2015). Improved Photographic Representation of Human Vision for Landscape Assessment. http://creativecommons.org/licenses/by/3.0/

Campbell, J. M. (1983). Ambient stressors. Environment and Behavior, 15(3), 355-380. https://doi.org/10.1177/0013916583153005

Charney, I. (2007). The politics of design: Architecture, tall buildings and the skyline of central London. Area, 39(2), 195-205. https://doi.org/10.1111/j.1475-4762.2007.00741.x

City of London. (2020). Policy D8: Tall Buildings. In Draft New London Plan. Retrieved from https://www.london.gov.uk/what-we-do/planning/london-plan/new-london-plan/draft-newlondon-plan/chapter-3-design/policy-d8-tall-buildings

Craggs, D. (2018). Skyscraper development and the dynamics of crisis: The new London skyline and spatial recapitalization. Built Environment, 43(4), 500-519. https://doi.org/10.2148/benv.43.4.500

Ellard, C. (2015). Places of the Heart: The Psychogeography of Everyday Life. Bellevue Literary Press.

Evans, G. W., \& McCoy, J. M. (1998). When buildings don't work: The role of architecture in human health. Journal of Environmental Psychology, 18(1), 85-94. https://doi.org/10.1006/jevp.1998.0089 
Goldhagen, S. (2017). Welcome to your world. Harper.

Higuera-Trujillo, J. L., López-Tarruella Maldonado, J., \& Llinares Millán, C. (2017).

Psychological and physiological human responses to simulated and real environments: A comparison between Photographs, $360^{\circ}$ Panoramas, and Virtual Reality. Applied Ergonomics, 65, 398-409. https://doi.org/10.1016/j.apergo.2017.05.006

Joye, Y., \& Dewitte, S. (2016). Up speeds you down. Awe-evoking monumental buildings trigger behavioral and perceived freezing. Journal of Environmental Psychology, 47, 112125. https://doi.org/10.1016/j.jenvp.2016.05.001

Kaplan, R., \& Kaplan, S. (1989). The experience of nature: a psychological perspective. In The experience of nature: a psychological perspective. CUP Archive. https://doi.org/10.1097/00005053-199111000-00012

Kaplan, R., Kaplan, S., \& Brown, T. (1989). Environmental Preference: A Comparison of Four Domains of Predictors. Environment and Behavior, 21(5), 509-530. https://doi.org/10.1177/0013916589215001

Lederbogen, F., Kirsch, P., Haddad, L., Streit, F., Tost, H., Schuch, P., Wüst, S., Pruessner, J. C., Rietschel, M., Deuschle, M., \& Meyer-Lindenberg, A. (2011). City living and urban upbringing affect neural social stress processing in humans. Nature, 474(7352), 498-501. https://doi.org/10.1038/nature10190 
Lindal, P. J., \& Hartig, T. (2013). Architectural variation, building height, and the restorative quality of urban residential streetscapes. Journal of Environmental Psychology, 33, 26-36. https://doi.org/10.1016/j.jenvp.2012.09.003

Montgomery, C. (2013). Happy City: Transforming Our Lives Through Urban Design. Doubleday Canada.

Negami, H. R., Mazumder, R., Reardon, M., \& Ellard, C. G. (2018). Field analysis of psychological effects of urban design: a case study in Vancouver. Cities \& Health, 2(2), 106-115. https://doi.org/10.1080/23748834.2018.1548257

New London Architecture (2015). London Tall Buildings Survey 2015. Retrieved from: https://www.newlondonarchitecture.org/docs/tall_bldgs_survey_2015.pdf

New London Architecture (2020). London Tall Buildings Survey 2020. Retrieved from: https://www.newlondonarchitecture.org/docs/tall_bldgs_survey_2020.pdf

Parker, M. (2015). Vertical capitalism: Skyscrapers and organization. Culture and Organization, 21(3), 217-234. https://doi.org/10.1080/14759551.2013.845566

Payne, A. F. H., Schell, A. M., \& Dawson, M. E. (2016). Lapses in skin conductance responding across anatomical sites: Comparison of fingers, feet, forehead, and wrist. Psychophysiology, 53(7), 1084-1092. https://doi.org/10.1111/psyp.12643 
Saga, K. (2002). Structure and function of human sweat glands studied with histochemistry and cytochemistry. Progress in Histochemistry and Cytochemistry, 37(4), 323-386. https://doi.org/10.1016/S0079-6336(02)80005-5

Stamps III, A. E. (n.d.). Visual permeability, locomotive permeability, safety, and enclosure. Environment and Behavior, 37(5), 587-619.

Stamps, A. E., \& Smith, S. (2002). Environmental enclosure in urban settings. Environment and Behavior, 34(6), 781-794. https://doi.org/10.1177/001391602237246

Stemmler, G. (1987). Standardization Within Subjects: A Critique of Ben-Shakhar's Conclusions. Psychophysiology, 24(2), 243-246. https://doi.org/10.1111/j.14698986.1987.tb00286.x

Tall Buildings, C., \& Habitats, U. (n.d.). CBTUH Year in Review: Tall Trends of 2018. http://www.skyscrapercenter.com/research/CTBUH_ResearchReport_2018YearInReview.p df

The Guardian Editorial Team (2020). The Guardian view on the UK housing crisis: no plan to fix it. https://www.theguardian.com/commentisfree/2020/jan/05/the-guardian-view-on-theuk-housing-crisis-no-plan-to-fix-it

Thiel, P., Harrison, E. D., \& Alden, R. S. (1986). The perception of spatial enclosure as a function of the position of architectural surfaces. Environment and Behavior, 18(2), 227245. https://doi.org/10.1177/0013916586182005 
United Nations Development Programme. (2014). World Urbanization Prospects: The 2014 Revision, Highlights (ST/ESA/SER.A/352). In New York, United (p. 32). https://doi.org/10.4054/DemRes.2005.12.9

van Dooren, M., de Vries, J. J. G. G. J., \& Janssen, J. H. (2012). Emotional sweating across the body: Comparing 16 different skin conductance measurement locations. Physiology and Behavior, 106(2), 298-304. https://doi.org/10.1016/j.physbeh.2012.01.020

Vartanian, O., Navarrete, G., Chatterjee, A., Fich, L. B., Gonzalez-Mora, J. L., Leder, H., Modroño, C., Nadal, M., Rostrup, N., \& Skov, M. (2015). Architectural design and the brain: Effects of ceiling height and perceived enclosure on beauty judgments and approachavoidance decisions. Journal of Environmental Psychology, 41, 10-18. https://doi.org/10.1016/j.jenvp.2014.11.006

Zarghami, E., Karimimoshaver, M., Ghanbaran, A., \& Saadati Vaghar, P. (2019). Assessing the oppressive impact of the form of tall buildings on citizens: Height, width, and height-towidth ratio. Environmental Impact Assessment Review, 79, 106287. https://doi.org/10.1016/j.eiar.2019.106287 